\title{
O DISCURSO OUTRO EM NARRATIVAS FICCIONAIS E NÃO FICCIONAIS
}

\section{SPEECH OTHER IN FICTIONAL AND NON-FICTIONAL NARRATIVES}

\author{
Tatiana Simões e Luna* \\ Universidade Federal de Pernambuco, Recife, PE, Brasil \\ Dóris de Arruda C. da Cunba** \\ Universidade Federal de Pernambuco, Recife, PE, Brasil
}

Resumo: Narrativas são formas discursivas cuja natureza é propensa à manifestacãõo da pluralidade de vozes. Tradicionalmente, os estudos de RDO têm se dedicado ao estudo da prosa literária, observando o papel do discurso outro na relação entre autor, narrador e personagem. 0 objetivo deste artigo é descrever e comparar as formas e caracterizaç̃oes da RDO em gêneros de teor narrativo nõo ficcional e ficcional, com base nos estudos de Volochínov ([1929] 2007) e de Authier-Revuz ([1982] 2004, 1995, 1998, 2004, 2012, [2009] 2015): sete relatos de prática docente e cinco crônicas escritas por estudantes. 0 corpus é formado pelos textos vencedores do Programa Olimpíada de Língua Portuguesa Escrevendo o Futuro 2014 na categoria crônica e analisado sob o prisma metodológico qualitativo-interpretativo. Os resultados apontam que o uso mais diversificado das formas de RDO não se vincula ao caráter literário da narrativa, mas à maior autonomia discursiva do sujeito escrevente.

Palavras-chave: narrativa; discurso outro; discursividade escrita; crônica; relato.

\begin{abstract}
Narratives are discursive practices whose nature are inclined to the expression of voices plurality. Traditionally, RDO studies have been devoted to the analysis of the literary prose, by observing the role of the discourse of the Other in the relationship between the author, the narrator and the character. This article aims at describing and comparing the forms and characterization of RDO in non-fictional and fictional genres in regard to narrative wording, based on the studies of Volochinov ([1929]2007) and Authier-Revuz ([1982]2004, 1995, 1998, 2004, 2012, [2009]2015): seven teaching practice reports and five chronicles written by students. The corpus is composed by the prizewinning texts from the Programa Olímpiada de Língua Portuguesa Escrevendo o Futuro 2014 (Portuguese Language Olympics Writing the Future 2014 Program) in the category of chronicles and analyzed under the qualitative-interpretative methodological perspective. The results indicate that the most diversified use of the RDO forms is not linked to the literary quality of the narrative, but to the major discursive autonomy of the writing subject.
\end{abstract}

Keywords: Narrative; Discourse of the Other; Written Discursivity; Chronicle; Report.

* Universidade Federal de Pernambuco - UFPE, Recife, PE, Brasil; Programa Capes/COFECUB; simoes.luna@gmail.com

** Universidade Federal de Pernambuco - UFPE, UNICAP, CNPQ, Recife, PE, Brasil; Programa Capes/COFECUB; dorisarrudacunha@gmail.com

http://dx.doi.org/10.11606/issn.2236-4242.v31i3p167-190

Todo conteúdo da Linha D'Água está sob Licença Creative Commons Attribution-NonCommercial 4.0 International License 
Linha D'Água (Online), São Paulo, v. 31, n. 3, p. 167-190, set.-dez. 2018

\section{Introdução}

Narrativas são formas discursivas tradicionalmente tomadas como exemplo dos estudos sobre a representação do discurso outro $\left(\mathrm{RDO}^{1}\right)$, dada sua natureza heterogênea, marcada por uma miscelânea de vozes cuja finalidade é reportar um fato ou acontecimento, sejam elas do narrador, das personagens e do próprio escritor, cuja imagem se faz representar textualmente, na narração literária; sejam elas dos sujeitos representados e do enunciador, na narração prosaica. Este artigo apresenta um estudo da RDO com o objetivo de descrevê-las e compará-las em narrativas ficcionais e não ficcionais, observando o uso das formas de RDO em relação ao domínio do gênero pelo sujeito escrevente.

A fundamentação teórico-metodológica deste trabalho está centrada nas contribuições de Volochínov ([1929] 2017), que estuda os esquemas de transmissão do discurso outro (direto, indireto e indireto livre) sob o viés da recepção e da circulação de sentido, e nos estudos de Authier-Revuz ([1982] 2004, 2012, [2004] 2015), que acrescentam às categorias tradicionais de RDO indicadas a modalização em discurso segundo e a modalização autonímica de empréstimo, sendo esta um fenômeno recorrente nos textos analisados.

Dada os limites de extensão do próprio artigo, faremos um resumo de nossas opções teóricas sem a pretensão de expor a profundidade de pensamento desses autores. Os dados selecionados para esta pesquisa ${ }^{2}$ são formados por doze textos premiados na categoria crônica do Programa Olimpíada de Língua Portuguesa Escrevendo o Futuro (doravante, OLPEF), sendo sete relatos de prática escritos por professores e cinco crônicas escritas por estudantes ${ }^{3}$.

1 Adotamos a sigla RDO, em português, tradução de Représentation du discours autre (RDA), em consonância com Authier-Revuz (2015), para quem essa nomenclatura é mais coerente que discurso reportado por evitar a associação com um enunciado necessariamente precedente e por delimitar claramente, no âmbito da atividade metalinguageira, o campo da alteridade, do dizer sobre o outro, em relação ao campo da autorrepresentação do dizer, do discurso que comenta sobre si em seu próprio processo de realização.

2 Os dados foram colhidos durante o estágio doutoral sanduíche de uma das autoras realizado na Université Paris-Nanterre, sob a supervisão da professora Frédérique Sitri.

3 A escolha desse corpus permitiu-nos atender aos objetivos propostos pelo projeto Representação do Discurso Outro e discursividade escrita: estudo comparativo em francês, espanhol e português brasileiro, financiado pelo Programa Capes/COFECUB, coordenado no Brasil por

LUNA, T. S.; CUNHA, D. A. C. 0 discurso outro em narrativas ficcionais e não ficcionais

Todo conteúdo da Linha D'Água está sob Licença Creative Commons Attribution-NonCommercial 4.0 International License 
Linha D'Água (Online), São Paulo, v. 31, n. 3, p. 167-190, set.-dez. 2018

A OLPEF é um programa de formação docente que visa à melhoria do ensino-aprendizagem da produção escrita nas escolas públicas, por meio da metodologia da sequência didática (DOLZ, SCHNEUWLY, 2004). Bienalmente, realiza-se um concurso de textos dividido em quatro categorias ou gêneros: poema, memórias literárias, crônica e artigo de opinião. A OLPEF fornece uma série de materiais didáticos que orientam os professores a conduzir as atividades de preparação para a produção final do texto a ser encaminhado às comissões julgadoras; dentre eles, o principal é o Caderno do Professor (LAGINESTRA, PEREIRA, 2014), composto por uma série de oficinas voltadas para o ensino do gênero em foco, tendo uma duração média de dois meses e meio. Os professores cujos alunos chegaram à etapa semifinal da Olimpíada foram convidados a relatar sua experiência de ensino para participar de um concurso de relatos de prática. Os textos selecionados para esse trabalho foram os vencedores da edição de 2014, na categoria crônica: cinco crônicas estudantis ${ }^{4}$ e sete relatos de prática docentes acerca das oficinas sobre esse gênero ${ }^{5}$.

$\mathrm{Na}$ análise desse corpus, usaremos as definições de discurso reportado e de RDO dos autores citados como categorias de análise. Nas considerações finais, estabelecemos uma comparação entre o funcionamento das formas de RDO nos dois gêneros analisados, a crônica literária e o relato de prática.

Dóris de Arruda C. da Cunha, a saber: descrever as formas de RDO e classificá-las em função dos gêneros nos quais elas aparecem ou predominam; e comparar as caracterizações da RDO em línguas, discursos e gêneros equivalentes.

4 "Exclusividade", de Ester Raquel F. de Araújo, do Ceará; "O mundo de uma única cor", de Isabella Kétlin S. Barros, de Rondônia; "A Sociedade Secreta das Galinhas", de Alisson Henrique B. da Silva, de Minas Gerais; "Cavalgada solitária", de Vítor Luiz Kohler, do Paraná; e "Sonoro tic-tac...", de Cleiton Jesus A. Pereira, do Rio Grande do Sul.

5 "Navegar é preciso", de Veralice Maria Z. Bertazzo, do Mato Grosso; "Garimpando diamantes em meio a árvores e baralhos", de José Francisco Bertolo, de São Paulo; "Pelos caminhos do aprendizado", de Vanicléia de O. S. Rebelo, do Paraná; "Professor: artista de muitos palcos", de Sirlei de S. R. Alves, de Minas Gerais; "Uma dose de palavras: um novo ser", de José Elonilson P. da Costa, do Acre; "De professora à educadora: Semeando o Futuro", de Antonia Genizelda Teixeira Lima, do Ceará; "Sem medo das inconstâncias vividas", de Maria Juciele A. S. Silva, de Alagoas.

LUNA, T. S.; CUNHA, D. A. C. 0 discurso outro em narrativas ficcionais e não ficcionais Todo conteúdo da Linha D'Água está sob Licença Creative Commons Attribution-NonCommercial 4.0 International License 
Linha D'Água (Online), São Paulo, v. 31, n. 3, p. 167-190, set.-dez. 2018

\section{Breve ancoragem dos estudos sobre a representação do discurso outro}

Discurso citado, discurso reportado, citação, discurso de outrem, discurso alheio, vozes, vozes alheias, discurso do outro, discurso outro são alguns dos nomes atribuídos ao ato de se inscrever, explicitamente ou não, um enunciado oriundo de fonte(s) outra(s) no fio discursivo. Diferentes formas de nomeação refletem os diferentes enfoques teóricos das escolas e dos pesquisadores dedicados a esse tema. Tradicionalmente as gramáticas normativas e pedagógicas apresentam uma visão limitada desse fenômeno, pois o entendem como típico apenas da esfera literária, enfatizam a descrição de seus aspectos formais (pessoa do verbo, tempo e modo verbal, verbos dicendi, sinais de pontuação, construção sintática, exercícios de transformações morfossintáticas na passagem do discurso direto para o indireto) e reconhecem apenas três formas de manifestação, denominadas tipos de discurso direto, indireto e indireto livre. A exemplo disso, segue a definição dada pela Nova Gramática do Português Contemporâneo:

Para dar-nos a conhecer os pensamentos e as palavras de personagens reais ou fictícios, dispõe o narrador de três moldes linguísticos diversos, conhecidos pelos nomes de: a) Discurso (ou estilo) direto; b) Discurso (ou estilo) indireto; c) Discurso (ou estilo) indireto livre. (CUNHA, CINTRA, 2008, p. 649).

A presença do outro, porém, se revela nas mais variadas esferas discursivas, seja cotidiana, seja literária, seja midiática, seja administrativa, seja acadêmica, seja jurídica etc., conforme atestam os trabalhos de Cunha (2011,2015). Todo discurso tem uma dupla, ou melhor, tripla orientação: voltado para o seu objeto temático, enquanto discurso comum, e voltado para o discurso do outro, enquanto resposta às vozes que lhe precedem e lhe sucedem (as possiveis réplicas do(s) destinatário(s)). Além disso, mais do que traços formais o que caracteriza o discurso outro é o seu conteúdo semântico, a sua construção estilístico-composicional e o seu propósito ou intuito discursivo, isto é, as razões de um enunciado reportar ou evocar outro em determinado contexto enunciativo e sócio-histórico-cultural.

A concepção instrumental de língua que subjaz a definição gramatical acima supõe que as formas de se representar o discurso outro são fixas, prontas, de que o

LUNA, T. S.; CUNHA, D. A. C. 0 discurso outro em narrativas ficcionais e nõo ficcionais Todo conteúdo da Linha D'Água está sob Licença Creative Commons Attribution-NonCommercial 4.0 International License 
Linha D'Água (Online), São Paulo, v. 31, n. 3, p. 167-190, set.-dez. 2018

escritor se serve quando deseja reportar a fala e/ou o pensamento das personagens. No entanto, cada um desses três tipos clássicos de discurso apresenta uma gama de variações, como mostra o estudo de Volochínov ([1929] 2017).

$\mathrm{O}$ autor defende que o discurso outro seja analisado sob uma perspectiva sociológica, pois é preciso compreender o porquê de certo discurso ser reportado pelo autor, em dada situação; o modo como ele é percebido pelo(s) destinatário(s), em dado contexto receptivo; as réplicas interiores e reações verbais que ele suscita; o conteúdo que ele carrega e a forma como ele é representado (as modificações sintáticas, estilísticas e composicionais que ocorrem na sua própria construção e no enunciado autoral que o incorpora).

Os esquemas básicos de transmissão do discurso alheio - discurso direto, indireto e indireto livre - só podem surgir e se formar em relação às tendências predominantes de percepção do discurso alheio, as quais são definidas socialmente. É a "sociedade que seleciona e gramaticaliza os aspectos da percepção ativa e avaliativa do enunciado alheio que são socialmente pertinentes e constantes e, por conseguinte, baseiam-se na própria existência econômica ${ }^{6}$ de uma coletividade falante." (VOLOCHÍNOV, [1929] 2017, p. 252). Em outras palavras, o autor considera que a conjuntura socioeconômica em um determinado momento histórico determina as condições da comunicação discursiva e, por conseguinte, as formas de transmissão do discurso alheio, suas variantes e as modificações dessas variantes.

Cada tipo de discurso apresenta variantes que realizam o estilo linear ou pictórico ${ }^{7}$ de representar o enunciado alheio. A construção indireta incorpora os elementos afetivos-emocionais do enunciado alheio em seu conteúdo, sob a forma de comentários no contexto narrativo. Em uma de suas variações de estilo linear, a “modificação analítico-objetual” (VOLOCHÍNOV, [1929] 2017, p. 272),

6 A influência marxista no trabalho de Volochínov é questionada por alguns autores, dentre eles, Sériot (2015). Tal polêmica foge ao escopo do nosso trabalho e, por isso, não iremos explorá-la.

7 O estilo linear é aquele em que o discurso é representado de modo a assegurar sua autenticidade, preservando-se as fronteiras entre o contexto autoral e o enunciado alheio. $O$ estilo pictórico enfraquece essas fronteiras, apagando os contornos nítidos e exteriores entre os discursos, sendo mais propício aos modelos mistos de transmissão do discurso outro e às variações desses esquemas. (VOLOCHÍNOV, [1929] 2017)

LUNA, T. S.; CUNHA, D. A. C. 0 discurso outro em narrativas ficcionais e não ficcionais Todo conteúdo da Linha D'Água está sob Licença Creative Commons Attribution-NonCommercial 4.0 International License 
Linha D'Água (Online), São Paulo, v. 31, n. 3, p. 167-190, set.-dez. 2018

o discurso indireto prioriza a posição semântica e objetiva do enunciado alheio, introduzindo os aspectos de sua construção verbal e formal que têm significação temática no contexto autoral ou transmitindo-os de modo temático. Já a "modificação analítico-verbal” (VOLOCHÍNOV, [1929] 2017, p. 273) prioriza o caráter subjetivo e estilístico do enunciado alheio, introduzindo palavras e modos de dizer característicos do sujeito representado, inclusive com expressões entre aspas.

A construção direta, em sua forma padrão, apresenta o enunciado alheio como um todo compacto, mantendo sua integridade semântica e expressiva diante do contexto autoral. Esse esquema de transmissão, no entanto, apresenta diversas modificações em que os limites entre os discursos são enfraquecidos, ocorrendo troca mútua de palavras e de entonação entre eles. O "discurso direto preparado" ocorre quando o enunciado alheio é antecipado pelo contexto autoral, sendo normalmente precedido pelo discurso indireto ou indireto livre (VOLOCHÍNOV, [1929] 2017, p. 278). A modificação "discurso direto reificado" é aquela em que a caracterização do enunciado alheio é mais importante que seu conteúdo semântico (VOLOCHÍNOV, [1929] 2017, p. 279). A descrição da personagem (ou do sujeito representado, no caso dos gêneros não literários) é mais privilegiada que o aspecto temático do discurso outro.

Em uma escala gradativa de contaminação e interferência discursiva, temse ainda o "discurso alheio antecipado, disperso e oculto no contexto autoral" que irrompe no enunciado, vindo diretamente do sujeito representado; é o caso em que o contexto autoral é perpassado pelo modo de dizer e pela entonação do outro (VOLOCHÍNOV, [1929] 2017, p. 280). A modificação "discurso direto retórico", a exemplo da pergunta e da exclamação retóricas, aproxima-se do discurso indireto livre, pois se encontra na fronteira entre o enunciado autoral e o alheio, prevalecendo, contudo, a voz do autor que fala em nome do outro (VOLOCHÍNOV, [1929] 2017, p. 285).

O fenômeno da contaminação e da interferência entre os discursos atinge seu ápice no indireto livre em que as palavras compartilham simultaneamente duas entonações, dois contextos, dois discursos - o enunciado autoral e o alheio. Nesse esquema de transmissão, há fusão entre dois discursos com orientações diferentes: a narrativa é construída com base nos tons das personagens, e o discurso destas

LUNA, T. S.; CUNHA, D. A. C. 0 discurso outro em narrativas ficcionais e não ficcionais Todo conteúdo da Linha D'Água está sob Licença Creative Commons Attribution-NonCommercial 4.0 International License 
é construído com base nos tons do autor. Em outros termos, o enunciado alheio ganha autonomia e se posiciona ao lado do contexto autoral.

Um dos pilares da teoria dialógica de Volochínov se encontra no reconhecimento de que a voz alheia, exterior penetra constitutivamente o campo do dizer. Toda palavra está orientada dialogicamente para outros discursos, que lhe precedem e que the sucedem. Ancorada nesse princípio, na noção de interdiscurso da teoria pecheutiana e de sujeito clivado da psicanálise freudo-lacaniana, Authier-Revuz ([1982] 2004) desenvolve um estudo das formas de RDO que considera a heterogeneidade radical de todo enunciado.

Amparada na noção de que o discurso outro é "o discurso dentro do discurso, o enunciado dentro do enunciado, mas ao mesmo tempo é também o discurso sobre o discurso, o enunciado sobre o enunciado" de Volochínov ([1929] 2017, p. 249) e na noção de autonímia ${ }^{8}$ de Rey-Debove, a autora desenvolve seus estudos sobre a metalinguagem e, nesse campo, inclui as formas de RDO, realizando uma análise do ponto de vista da língua, desmembrada nos planos semântico, semiótico e enunciativo.

Para a autora, a mostração do dizer outro está relacionada à necessidade que tem o sujeito de circunscrever o discurso, de delimitar o próprio espaço no campo enunciativo, de controlar o sentido que lhe escapa. As formas da RDO evidenciam a negociação que o sujeito falante realiza com a heterogeneidade constitutiva de todo e qualquer discurso.

Através dessas marcas, designando o outro localizadamente, o sujeito empenha-se em fortalecer o estatuto do um. É nesse sentido que a heterogeneidade mostrada pode ser considerada como um modo de denegação no discurso da heterogeneidade constitutiva que depende do outro no um. (AUTHIER-REVUZ, [1982] 2004, p. 74, grifos da autora)

A heterogeneidade constitutiva, enquanto condição de existência do discurso, põe em cena o papel do destinatário e sua capacidade de reconhecer e de interpretar o dizer alheio, oriundo de outro lugar, com base em certos traços e indícios de

8 Segundo Authier-Revuz (1998), a autonímia ocorre quando há uso e menção da palavra simultaneamente.

LUNA, T. S.; CUNHA, D. A. C. 0 discurso outro em narrativas ficcionais e nõo ficcionais Todo conteúdo da Linha D'Água está sob Licença Creative Commons Attribution-NonCommercial 4.0 International License 
Linha D'Água (Online), São Paulo, v. 31, n. 3, p. 167-190, set.-dez. 2018

contextualização que irrompem no discurso (AUTHIER-REVUZ, 2012), como os estereótipos e os clichês discursivos, as tautologias e as nominalizações.

As formas da heterogeneidade mostrada ou representada, segundo a autora ([2004] 2015), vinculam-se a dois atos de enunciação, a duas localizações espáciotemporais e a dois sujeitos, autor e destinatário, do contexto representado e do contexto que o representa, produzindo, assim, três ancoragens enunciativas: única; disjunta e hierarquizada; dissociada, partilhada ou dividida. No plano semântico, elas caracterizam-se por representar o discurso outro enquanto fonte (modalização) ou objeto do dizer (predicação) e, no plano semiótico, por representá-lo por meio da paráfrase ou da autonomização.

O campo da RDO estrutura-se a partir de cinco modos de combinação desses três planos que englobam formas linguístico-estilísticas marcadas e não marcadas (AUTHIER-REVUZ, [2004] 2015):

- $\quad$ O discurso indireto (DI) representa o enunciado alheio enquanto objeto do dizer por meio da paráfrase, caracterizando-se, no plano semântico, pela predicação e, nos planos semiótico e enunciativo, pela integração à ancoragem do enunciado fonte. Ou seja, o discurso fonte e o enunciado alheio são estruturalmente homogêneos, pois aquele integra o outro em sua construção sintática.

- O discurso direto (DD) expõe o dizer alheio, segmentando-o localmente do contexto enunciativo. $\mathrm{O}$ discurso outro é objeto do dizer e representado por meio da autonímia, sendo assim heterogêneo e disjunto ao enunciado fonte nos planos sintático, semiótico e enunciativo. $\mathrm{O}$ discurso direto livre, apesar de não marcado, caracteriza-se como um DD interpretativo.

- O discurso indireto livre (DI) é um enunciado bivocal em que o discurso fonte transmite dizeres, pensamentos e sentimentos do sujeito representado, tomando-o como objeto do dizer. Caracteriza-se pela imbricação de vozes, pela mistura enunciativa, pois é um dizer partilhado pelos enunciados autoral e alheio, em que não se sabe precisar a responsabilidade enunciativa.

- A modalização em discurso segundo (MAS) corresponde ao dizer que fala a partir de outro, que recupera outro discurso como fonte para abordar certo

LUNA, T. S.; CUNHA, D. A. C. 0 discurso outro em narrativas ficcionais e não ficcionais Todo conteúdo da Linha D'Água está sob Licença Creative Commons Attribution-NonCommercial 4.0 International License 
tema ou modo de expressar. Produzida por meio de paráfrase, a MAS “é a zona, dupla, da modalização do dizer pelo discurso outro, onde o outro não é mais aquilo de que se fala, mas o que interfere no dizer, o que o altera" (AUTHIER-REVUZ, [2004] 2015, p. 19). A ancoragem enunciativa, nesse caso, é unificada.

- A modalização autonímica de empréstimo (MAE) é "definida pelo fato que falamos de um objeto qualquer a partir de um outro discurso, cuja imagem passa pela exposição das palavras" (AUTHIER-REVUZ, [2004] 2015, p. 16). A MAE representa o enunciado alheio a partir do modo de expressão de outrem ou da forma como o enunciador o designa e interpreta, através de uma variedade de marcas, explícitas (aspas) e implícitas (alusão).

As aspas são um sinal a ser interpretado; de natureza lacunar, são polissêmicas produzindo efeitos de sentido diversos (AUTHIER-REVUZ, 1998). Podem assinalar a não coincidência entre as palavras e as coisas, configurar "ilhas textuais" enquanto empréstimo a outro discurso, denotar o respeito à autoridade do outro, certo distanciamento em relação esse dizer ou até mesmo discordância. A alusão, por sua vez, encontra-se no limiar entre a heterogeneidade mostrada do dizer e a heterogeneidade constitutiva do discurso. Sendo uma forma não marcada, exige um duplo movimento do destinatário: o reconhecimento do segmento outro na cadeia verbal e identificação da fonte desse dizer no espaço do já dito. Ela é simultaneamente uma forma de dialogismo interdiscursivo, por evocar as palavras alheias não claramente determinadas e interlocutivo, por depender da recepção daquele a quem ela se dirige (AUTHIER-REVUZ, [2004] 2015). As formas de $\mathrm{RDO}$ e os indícios dialógicos aqui descritos são recorrentes no corpus em análise como veremos nas seções 4 e 5 .

\section{Narrativas ficcionais e não ficcionais: a crônica literária e o relato de prática}

Textos narrativos são, em geral, caracterizados por certos traços prototípicos: unidade de ação, sucessão temporal dos fatos ou acontecimentos, indicação temporal

LUNA, T. S.; CUNHA, D. A. C. 0 discurso outro em narrativas ficcionais e não ficcionais Todo conteúdo da Linha D'Água está sob Licença Creative Commons Attribution-NonCommercial 4.0 International License 
e locativa, presença de atores sociais (narração não ficcional) ou personagens (narração ficcional). São esses traços comuns às crônicas literárias e aos relatos de prática que nos permitem caracterizar ambos os gêneros como narrativos ${ }^{9}$. Se bem que haja elementos de uma organização composicional similar, há diversas peculiaridades atinentes ao caráter de (não) ficcionalidade, bem como à esfera de atividade a que se vinculam, conforme as características exigidas pelos critérios de avaliação propostos pela própria OLPEF $^{10}$ (LAGINESTRA, PEREIRA, 2014; OLIMPÍADA, 2016).

Os gêneros do domínio artístico e literário são mais propícios à criatividade e ao investimento estilístico individual, por isso, as crônicas são bastantes plásticas e flexíveis, admitindo vários formatos e tons, como o humorístico, o lírico, o filosófico e o crítico. Tomam como fonte temática episódios cotidianos, fatos inusitados, curiosos e/ou noticiados no jornal, conferindo-lhes um olhar ou reflexão singular do autor, que, em geral, faz uso do registro coloquial e estabelece uma conversa com o leitor.

Já os relatos de prática são gêneros do universo pedagógico e profissional que ajudam o professor a refletir sobre sua condução didática e avaliá-la, bem como a construir a sua própria identidade profissional; na medida em que ele toma uma posição relativa às orientações pedagógicas e aos materiais didáticos recebidos, à organização escolar e a seus membros, ao perfil comportamento e cognitivo dos alunos e à sua própria metodologia. Iremos observar, nas seções seguintes, a relação entre os esquemas de transmissão do discurso outro, as formas de RDO e os dois gêneros do narrar indicados: a crônica literária e o relato de experiência.

\section{0 discurso outro em formas narrativas ficcionais}

9 Não fazemos distinção entre gêneros do narrar e do relatar, tal qual Dolz e Schneuwly (2004), por considerarmos que as similaridades entre tais tipos linguísticos superam as diferenças, afinal ambos contam experiências passadas consistentes que correspondem a uma ordenação de eventos supostamente reais.

10 Os critérios gerais de avaliação são a adequação ao tema e ao gênero, as marcas de autoria e as convenções da escrita. Mas o material didático encaminha a construção de uma crônica narrativa, ao exigir os seguintes elementos nas oficinas: foco narrativo, cenário, enredo, desfecho e personagens.

LUNA, T. S.; CUNHA, D. A. C. 0 discurso outro em narrativas ficcionais e não ficcionais Todo conteúdo da Linha D'Água está sob Licença Creative Commons Attribution-NonCommercial 4.0 International License 
Linha D'Água (Online), São Paulo, v. 31, n. 3, p. 167-190, set.-dez. 2018

A crônica como qualquer gênero literário prosaico é marcada por falas das personagens que contribuem com a feição da tessitura ficcional e a tornam mais verossímil. A presença de diálogos, seja entre as personagens, seja entre autornarrador e leitor, e de verbos introdutores de discurso (dicendi) são algumas das características do gênero apresentadas aos alunos durante as oficinas da OLPEF. O Caderno do professor (LAGINESTRA, PEREIRA, 2014) orienta-o a indicar aos alunos o uso desses dois elementos na construção do texto a fim de conferir maior vivacidade e agilidade à narrativa. É de se supor, portanto, que os textos vencedores apresentem maestria no manejo de tais características, porém nem todos as evidenciam.

Das cinco crônicas premiadas, apenas duas dinamizaram a história através de diálogos entre as personagens. As demais exploram poucos tipos de heterogeneidade mostrada, fazendo uso de apenas uma ou duas formas, salvo a crônica $A$ sociedade secreta das galinhas que maneja diversos modos de RDO e os entrelaça. Nos textos analisados, podemos observar o uso do DI, da MAE (por meio das aspas ou da alusão), do DIL e do $\mathrm{DD}^{11}$. O primeiro ocorre principalmente em sua modificação analítico-objetual, pois os verbos introdutores desse dizer - "relatar", "chamar", "pedir" e o próprio "dizer" - destacam o conteúdo associado ao ato de reportar uma fala, como se verifica nas crônicas:

- Cavalgada solitária, de Vítor Kohler (OLPEF, 2014), "às vezes alguém diz que ouve o vento trazendo o barulho da cavalgada no peito de Darci", "Carlão (esse era seu nome) relatou que estivera com Darci até tarde da noite passada", "As poucas pessoas com quem tinha algum contato o chamavam de Darci.";

- Sonoro tic-tac..., de Cleiton Pereira (OLPEF, 2014), "Todos da família que estavam próximos elogiaram o objeto amado.”, cujo acento apreciativo do verbo indica o ponto de vista dos sujeitos representados;

- Exclusividade, de Ester Araújo (OLPEF, 2014), "como quem suplica, pedi um desconto", cujo verbo ilocutório ressalta o conteúdo semântico do dizer, apesar de

1 Não há uso significativo da modalização em discurso segundo. O DI e o DD são transmitidos ora pelo esquemas tradicionais, ora pelas suas variantes e modificações dessas variantes, alternando entre o estilo linear e pictórico de representar a voz alheia.

LUNA, T. S.; CUNHA, D. A. C. 0 discurso outro em narrativas ficcionais e não ficcionais Todo conteúdo da Linha D'Água está sob Licença Creative Commons Attribution-NonCommercial 4.0 International License 
comentário apreciativo antecedente recair no modo de expressão do dizer, o que remete à "modificação analítico-verbal" do DI.

A modalização autonímica de empréstimo é recorrente na crônica $O$ mundo de uma única cor, de Isabella Barros (OLPEF, 2014). O verso inicial da canção Paisagem da janela, de Beto Guedes - "Da janela lateral do quarto de dormir" - abre o texto, sendo demarcado por aspas. O reconhecimento dessa letra do cancioneiro popular pelo leitor é facilitado pelo próprio comentário apreciativo que a sucede - "Parece letra de música e é, mas a realidade não é tão poética assim" - em que se observam outras alusões imbricadas, de caráter interpretativo: a um dito popular ou, mais especificamente, à expressão cristalizada ou figée $e^{12}$ "Parece, mas não é"; e a dizeres do senso comum - "A vida não é poética", "A vida não é uma novela", "A realidade não é um conto de fadas"-, aqui materializados na variação "A realidade não é tão poética assim”.

A importância desse verso é tal que ele é retomado, sem aspas, alguns parágrafos adiante, por apontar para o local (topoi) a partir do qual a narradora-personagem observa sua rua e expõe seu ponto de vista sobre a temática geral proposta pela OLPEF - O lugar onde vivo. Ao final, a autora cita outro verso musical para assinalar a sua mudança de posicionamento: um trecho da música Fascinação, de Elis Regina, - "fascina, inebria e entontece" -, delimitado pelo uso das aspas e facilmente identificado pelo comentário posterior - "mas aí já é outra música". Ocorre, no entanto, uma retomada parcial nesse movimento de citar, já que o verso-fonte é "prende, inebria e entontece". Podemos atribuir essa retomada parcial à parca experiência da autora, uma jovem estudante, com esse universo cultural, ou mesmo a um processo de estilização, de modificação proposital do enunciado-fonte para lhe imprimir novo acento apreciativo.

Em uma direção mais interpretativa, encontramos ocorrência significativa de DIL na crônica Cavalgada solitária (ver anexos), em que o discurso do

12 O figement, de acordo com Authier-Revuz (1995), é uma sequência ou expressão característica de uma língua (forma quase composta fixa ou quase fixa), de um texto (sintagma recorrente em um texto) ou de um gênero (sintagmas recorrentes em um texto suscetíveis de aparecer em outros textos pertencentes ao mesmo gênero). Trata-se de um traço ou indício dialógico, um clichê ou estereótipo, reconhecido por sua saliência temática ou estilística.

LUNA, T. S.; CUNHA, D. A. C. 0 discurso outro em narrativas ficcionais e não ficcionais Todo conteúdo da Linha D'Água está sob Licença Creative Commons Attribution-NonCommercial 4.0 International License 
Linha D'Água (Online), São Paulo, v. 31, n. 3, p. 167-190, set.-dez. 2018

narrador-onisciente se amalgama com o pensamento da personagem. $\mathrm{O}$ futuro do pretérito do indicativo ("teria") e o pretérito imperfeito do subjuntivo ("tivesse"), nos enunciados (1) e (2), lançam esse dizer no mundo do possível, cuja enunciação é partida entre a narração e o discurso outro. $\mathrm{O}$ jogo de perguntas e respostas em (1), assim como o comentário enunciativo em (2), podem transmitir simultaneamente o diálogo interior do dono da chácara e as observações do narrador acerca do sumiço de "Cavalo Velho".

Certa manhã, por volta das dez e meia, o dono da Chácara Kohler, percebendo que Darci não havia descido para buscar água, subiu a ladeira que separava o espaço de conforto familiar, fartura, aconchego do outro lado. No topo da estrada, observou a pequena casa fechada, nenhum sinal de fumaça ou vida. Teria Cavalo Velho cavalgado para outras terras? Teria saído em busca de sua família, sua história, sua identidade? Não! Nada! (1) Nenhuma resposta ao chamado: "Darci!" "Cavalo Veio!"

Talvez tivesse saído, mas isso era algo que ele nunca havia feito sem antes buscar água, fazer o café humilde no fogão a lenha no canto do cômodo. (2)

Ainda nessa crônica, encontramos a modificação discurso direto retórico nos enunciados (3) e (4), que é uma variação do DD próxima ao DIL por apresentar mistura de vozes, mas com dominância do discurso autoral:

Preocupados, os dois arrombaram a porta e, para susto e tristeza, encontraram Cavalo Velho deitado, gelado e sem vida. Causa da morte? Ninguém sabe. Seu nome completo? Ninguém sabe. De onde veio? Ninguém sabe. Quem é sua família? Ninguém sabe. Seu nome seria de fato Darci? Ninguém sabe... (3)

Na mesma tarde a Funerária Daou, tradicional e conhecida como a mais humana da Lapa, desceu com o humilde caixão para buscar Darci após ter cumprido todas as exigências legais para sepultar Cavalo Velho como indigente. Causa da morte? Ninguém sabe. (4) Nenhum sinal de agressão, luta ou ferimento.

As perguntas retóricas podem ser atribuídas a diferentes personagens secundários que aparecem no enredo (a polícia, os funcionários da Funerária Daou, os

LUNA, T. S.; CUNHA, D. A. C. 0 discurso outro em narrativas ficcionais e ñ̃o ficcionais Todo conteúdo da Linha D'Água está sob Licença Creative Commons Attribution-NonCommercial 4.0 International License 
vizinhos), mas as respostas dadas remetem ao comentário apreciativo do narrador que evidencia a indigência da personagem central. A estruturação paralelística das perguntas e respostas também enfatiza a falta de identidade do protagonista.

O DD está presente na forma composicional dialogal que estrutura as crônicas $A$ sociedade secreta das galinhas, de Alisson Silva (OLPEF, 2014) e Sonoro tic-tac..., de Cleiton Pereira (OLPEF, 2014). Na segunda, encontram-se diversos planos enunciativos do DD, materializados em diversas modificações e variantes:

Perguntei pelos meus primos; logo veio a resposta:

- Tão na sanga, brincando. (1)

Prontamente me dirigi ao barranco e os observei na água. Mal me viram, já gritaram, em convite:

- Vem pra água! Vamos brincar! Está divertido! Vem! (2)

Por um momento resisti àquele convite sedutor. Mas não podia deixá-lo passar.

Necessitava brincar. Naquele momento! (3)

Comecei a buscar argumentos que ajudassem a me convencer do contrário:

- Não... Acho que venho amanhã. (4)

Mas a água... Ah, a água: límpida, morna e terna, como colo materno, com seu correr sereno e ritmado, cujo leito é areia clara.

- Shhhhh... - Chiava a água.

Pareço ouvir um murmúrio cantarolado, como se fosse mãe-d'água me hipnotizando. (5)

O riso dos meus primos... Tudo me levava a sucumbir ao desejo. A guerra em mim havia sido perdida. De repente, um grito ecoa na mata que nos rodeia e quebra minha hipnose:

- Filho, sai da água, agora! Tu vai ver quando chegar em casa, guri! (6)

Maldição! (7) Eu tinha entrado na água. De roupa e tudo.

Nos enunciados (1), (2) e (6), a variante "discurso direto preparado" é antecipada pelo DI cujos verbos dicendi - "perguntei”, "gritaram" e "ecoa” - e nominalizações - "resposta", "convite" e "grito" -, respectivamente, indicam o valor associado ao conteúdo temático do enunciado alheio e realizam a progressão semântica do texto, ordenando a sequência cronológica e causal dos fatos: (1) apresentação da situação e das personagens, (2) conflito interior da personagem entre brincar ou 
não na água, (6) clímax com a revelação de que a personagem brincou na água ${ }^{13}$. Em (4), é o discurso interior - "Comecei a buscar argumentos que..." - que antecipa e prepara o DD da personagem, relutante a entrar na água para não perder o seu relógio. Já (5) materializa a modificação do discurso direto reificado, em que o valor descritivo associado ao dizer outro - a caracterização poética da personagem "água" e do seu modo de expressão - ganha maior realce que o objeto desse dizer.

Os enunciados (3) e (7) assinalam casos de interferência discursiva, isto é, enunciados em que as vozes autoral e alheia se misturam. Em (3), a modificação discurso direto retórico traz uma fala que se aproxima do DIL, por transmitir um provável pensamento do outro, no entanto, se sobressai o comentário do narrador -personagem acerca da cena e do momento da personagem. A interrupção que poderia ser classificada como problema linguístico assinala a pausa para o posterior suspiro da personagem (exclamação retórica). Por fim, o comentário "Maldição!" (7) realiza a modificação discurso alheio, antecipado, disperso e oculto no contexto autoral, pois faz ressoar a voz e a entonação depreciativa do discurso interior da personagem no curso da narração, dado ter perdido seu precioso relógio.

$\mathrm{Na}$ crônica $A$ sociedade secreta das galinhas, o narrador conta a história através de um mosaico de falas, reportadas de forma dinâmica.

Chegando vagarosamente, Risoleta, a mais velha do quintal, resmunga:

- Loucos! De nada isso vai adiantar! O fim das galinhas caipiras já está traçado! Os humanos preferem aquelas metidas galinhas de granja! (1)

Zé retrucou prontamente:

- Não escutem essa velha gagá! A nossa solução é simples. A gente rouba um ônibus, bota a galinhada dentro e foge pra outra cidade. (2)

- Isso mesmo! - diz um franguinho valentão. - Muzambinho nem tem mar! Vamos é pra Porto de Galinhas! (3)

- Falar é fácil. Quem vai dirigir? Você? Prefiro virar ensopado - diz Risoleta, já se retirando, indignada...(4)

Alguém, do meio do galinheiro, em piados tristes, diz:

- Ela tem razão! Tudo isso é loucura. Somos meras galinhas...(5)

- É assim? Vamos ficar de bico calado? Querem acabar no almoço de sábado? $\mathrm{O}$ galo ergue a crista e sobe no poleiro mais alto. - O negócio é o seguinte: vamos

13 A brincadeira acarretou a perda do precioso relógio.

LUNA, T. S.; CUNHA, D. A. C. 0 discurso outro em narrativas ficcionais e não ficcionais Todo conteúdo da Linha D'Água está sob licença Creative Commons Attribution-NonCommercial 4.0 International license 
sequestrar o tal prefeito! É fácil! A gente avisa o papagaio que mora lá perto e depois... (6)

- Ei, pera aí! Olhem lá o garoto na janela! - O garnisé canta alto e todos olham em silêncio para mim. (7) Dona Terezinha rapidamente fecha a janela e me manda embora em um estalo. (8)

- Você não viu nada, mocinho - diz ela, apressada. - Leva umas bolachas pra comer depois. (9)

É uma boa hora de ir embora. (10)

O discurso introdutor das citações diretas, em geral, caracteriza a personagem, seu estado e modo de dizer, configurando a variante discurso direto reificado: "Chegando vagarosamente, Risoleta, a mais velha do quintal, resmunga" (1) e "O garnisé canta alto" (7). Nesses casos, o próprio verbo enfatiza o modo de expressão, enquanto em (2) marca o posicionamento da personagem: "Zé retrucou prontamente". Mesmo quando o autor da crônica mobiliza um verbo de conteúdo aparentemente "neutro", como "dizer", a descrição que o acompanha configura a variação acima: em (3), “diz um franguinho valentão”; em (4), “diz Risoleta, já se retirando, indignada...”; em (5), “Alguém, do meio do galinheiro, em piados tristes, diz"; em (9), "diz ela, apressada”.

Este ato de fala é apresentado pelo DI, no enunciado (8), que ressalta o movimento abrupto e imperativo da personagem: "Dona Terezinha rapidamente fecha a janela e me manda embora em um estalo”. Ao final do diálogo, no enunciado (10), o autor mobiliza o DIL, para reportar um dizer que tanto pode pertencer ao narrador-personagem comentando o desfecho da visita e espiada do galinheiro, como à própria personagem Dona Terezinha que ordena a retirada do narrador.

Parte dos atos de falas das personagens também evoca frases do senso comum, clichês discursivos ou figements, de forma alusiva, assinalando um dizer internamente dialogizado. Seguem os exemplos encontrados, retomados na crônica a partir de formas variantes (ver trechos em itálico): “O fim está próximo" em (1), “A solução é simples” em (2), "Falar é fácil” em (4), "Isso é loucura” em (5) e "É hora de partir" em (10). Em (6), encontramos mais um exemplo de MAE, uma frase do senso comum que retoma um título do cancioneiro popular brasileiro: O negócio é

LUNA, T. S.; CUNHA, D. A. C. 0 discurso outro em narrativas ficcionais e não ficcionais 
Linha D'Água (Online), São Paulo, v. 31, n. 3, p. 167-190, set.-dez. 2018

o seguinte, de Belchior. Tais expressões cristalizadas na comunicação cotidiana dão à crônica o tom coloquial próprio desse gênero.

\section{0 discurso outro em formas narrativas não ficcionais}

Os relatos de prática, por sua vez, contam as experiências vivenciadas pelo docente junto aos alunos, em sala de aula, durante o período de realização das oficinas da OLPEF, com base em seu olhar sobre si, sobre sua própria condução pedagógica e sobre seus alunos. Como todo relato, tais textos são construídos por uma diversidade de vozes convocadas pelo autor para reconstituir os acontecimentos, no caso, as aulas, que são marcadas pelas trocas de turnos entre professor e alunos.

Os sete relatos mobilizam formas da heterogeneidade mostrada que reportam tais dizeres - o DI, sobretudo, e o DD - e formas limítrofes entre a heterogeneidade mostrada e a constitutiva, como a alusão e as expressões cristalizadas ou figées $^{14}$, atendendo aos critérios de avaliação do concurso indicados no regulamento da OLPEF para alcançarem a premiação, dentre eles: a "presença de aspectos próprios da categoria relato" e a "originalidade" (OLPEF, 2016, p. 16) ${ }^{15}$.

O DI é uma das formas de citação mais utilizadas para reportar de modo resumitivo os atos de falas, as trocas de turnos entre alunos e mestre, que constituem o gênero aula. Em geral, o relato representa tais trocas em duplas camadas: o docente-autor representa sua própria voz e, a partir dela, os enunciados proferidos pelos alunos no contexto da aula por meio principalmente da modificação analítico-objetual do DI, como se pode verificar pelo uso de verbos dicendi que destacam o aspecto semântico do dizer ("ouvir", "reclamar”, "explicar”, "contar" e "pedir”). Por exemplo,

Ouvi várias vezes alunos reclamarem de tantas leituras e escritas (1). Nesses momentos explicava que o resultado de tanto trabalho viria e que poderiam verificar

14 Não há ocorrência significativa de modalização em discurso segundo nos relatos analisados.

15 Os critérios de avaliação dos relatos - presença de aspectos próprios da categoria do relato; narração de experiências significativas; indícios de reflexão sobre a prática; aspectos gerais de gramática e ortografia; originalidade - não foram alterados entre a quarta edição da OLPEF, em 2014, e a quinta edição, em 2016. Referenciamos esta última, porque o regulamento da edição anterior não está mais disponível.

LUNA, T. S.; CUNHA, D. A. C. 0 discurso outro em narrativas ficcionais e nõo ficcionais Todo conteúdo da Linha D'Água está sob Licença Creative Commons Attribution-NonCommercial 4.0 International License 
isso através dos textos que produziriam (2). Já estava se aproximando o momento da escrita final. Pedi que lançassem um olhar mais apurado para os fatos, lugares, pessoas que faziam parte da rotina de cada um, pois teriam a chance de reescrever a primeira crônica, ou se preferissem, poderiam escrever outra, caso tivessem tido uma ideia melhor (3). (REBELO, 2015)

Indo do estilo linear ao pictórico, a autora reporta a fala de seus alunos em (1), para, em seguida, representar outros turnos de sua fala, nos enunciados (2) e (3), em que faz alusão às orientações dadas no Caderno do Professor acerca da produção textual. Ilustra isso o trecho abaixo:

Apurado o olhar, anime a turma a sair a campo em busca de fotos instigantes: cenas da cidade; fatos do dia a dia; situações pitorescas; imagens que retratam a vida, os valores culturais e estéticos das pessoas da comunidade. Diga aos alunos que essas imagens serão o ponto de partida para a escrita da crônica que se transformará no produto final para ser apresentado na Olimpíada (LAGINESTRA, PEREIRA, 2014, p. 101).

O reconhecimento da MAE não marcada decorre do tipo de público-leitor que já possui conhecimento prévio do material didático da OLPEF - os avaliadores, em primeira instância, e a posteriori outros docentes participantes e interessados no Programa - e promove um efeito de identificação do sujeito-docente com a proposta da Olimpíada, favorecendo uma avaliação positiva do texto no concurso.

A representação do enunciado alheio também se dá através da citação indireta entrecortada ou acompanhada por outras formas de RDO. No excerto a seguir, destacam-se as citações diretas e os segmentos entre aspas -, os quais, respectivamente, reportam as vozes do alunado (enunciado (2)), respondendo aos atos de fala docentes (enunciado (1)), ou destacam termos metafóricos, títulos de projetos, de textos, de crônicas de autores célebres ou dos próprios alunos (enunciados (3) e (4)), como se pode verificar no exemplo:

Contei-lhes episódios da minha infância: como fui alfabetizada aos oito anos por meu pai, que escrevia o alfabeto com talos de plantas no chão de cimento grosso da tapera onde morávamos; do dia em que minhas pernas mais tremeram porque

LUNA, T. S.; CUNHA, D. A. C. 0 discurso outro em narrativas ficcionais e não ficcionais Todo conteúdo da Linha D'Água está sob Licença Creative Commons Attribution-NonCommercial 4.0 International License 
tive de esperar uma cobra atravessar a estrada, quando eu ia à casa da dona Rita, uma vizinha, buscar café emprestado porque chegara visita, de surpresa, em nossa casa (1). Essa estratégia foi muito bem acolhida. Era eu entrar na sala e alguém pedia "Professora, depois você conta mais uma história?" (2). Ali nasceu o projeto "Minha vida" (3), "filho" (4) da Olimpíada de Língua Portuguesa: um livro autobiográfico relatando episódios marcantes de nossas vidas. (ALVES, 2015)

O relato a seguir representa os fatos transcorridos na aula inicialmente através do DI, em sua modificação analítico-objetal, nos enunciados (1) e (2), que indicam as etapas da sequência didática conduzida verbalmente pelo docente, e em sua modificação analítico-verbal, no enunciado (3), que reporta a pergunta dirigida pelo professor aos alunos. Trata-se de uma construção próxima ao discurso direto livre, dado o uso autonímico do sinal de interrogação, porém a ancoragem enunciativa desse discurso citado é conjunta à do discurso citante, como mostra o distanciamento contextual indicado pelo pronome "aquele", caracterizando um DI. A citação direta, no enunciado (4), contendo a resposta de um dos alunos, dinamiza a construção narrativa que ainda é atravessada por dizeres alheios, reportados através de outras formas de RDO: a alusão a um frase do senso comum - "a força de vontade vence os obstáculos" - no enunciado (5) e a uma expressão cristalizada ou figée - "a receita do sucesso" - no enunciado (6).

$\mathrm{Na}$ aula seguinte, apresentei à classe um vídeo sobre $A$ Última Crônica, de Fernando Sabino (1). Queria tocá-los. Ao final do vídeo, perguntei o que eles sentiam naquele momento (2). Alguém seria capaz de escrever um texto semelhante àquele? (3) Do fundo da sala ecoou uma voz: "Fácil não é, professor, mas podemos tentar" (4). Era a resposta que eu queria, pois a força de vontade vence qualquer obstáculo (5). O desejo torna-se a receita para o sucesso (6).(COSTA, 2015)

Observa-se novamente a alternância entre o estilo linear e pictórico de representação do discurso outro. As alusões são um recurso frequente nos relatos. Dada a natureza literária do gênero em foco nas oficinas, os docentes apropriaram-se de traços estilístico-expressivos das crônicas escreveram seus textos com um toque de cronista, permeados de metáforas ou alusões metafóricas. A título de ilustração, 
No início eu não estava usando o material da Olimpíada. Assim, navegávamos sem rumo, remando contra a maré (1). Eu ainda estava com medo de enfrentar o desconhecido, pois sabia que nem sempre o dia estaria ensolarado e as velas ajustadas (2). Encontraria ventos, tempestades (3), então seria mais fácil deixar como estava. No entanto, após uma formação realizada na escola sobre a Olimpíada de Língua Portuguesa, onde o material foi apresentado, o mar dentro de mim se acalmou (4) e eu atraquei minhas aulas nas sequências didáticas da coleção (5). O Caderno do Professor seria nosso mapa rumo ao tesouro (6). (...) E assim... com o encerramento do trabalho e a classificação de uma crônica para a semifinal podemos gritar "terra à vista!" (7), atracar nossa embarcação e comemorar a conquista desse tesouro(8). Me considero descobridor de sete mares (9) e na próxima edição vou navegar para uma nova e extraordinária aventura (10). (BERTAZZO, 2015)

O teor alusivo do relato já se faz ver na titulação - "Navegar é preciso" - que remete ao título homônimo do poema de Fernando Pessoa, o qual, por sua vez, é inspirado em uma frase latina do general romano Pompeu, dita a marinheiros, amedrontados, que se recusavam a viajar durante a guerra. Ao longo do texto, vemos uma série de alusões metafóricas que promovem um efeito de identificação da professora, receosa em participar do Programa, com o discurso romano.

No enunciado (1), as frases feitas - "navegar sem rumo"e "remar contra a maré" - funcionam como expressões cristalizadas ou figements, que assinalam a presença de um outro difuso, disperso no discurso do senso comum. Nos enunciados (2) a (6), (8) e (10), há uma série de expressões metafóricas que remetem ao título - "dia ensolarado", "velas ajustadas", "ventos”, “tempestades”, "mar calmo", "atracar”, "mapa do tesouro", "navegar" e "aventura" - e evocam as histórias de aventuras e perigos no mar. O grito de "terra à vista", no enunciado (7), evoca a memória discursiva de uma dessas histórias, o relato de Pero Vaz Caminha sobre o "descobrimento" do Brasil, através de uma MAE explicitamente marcada por aspas. Em (9), a alusão à canção homônima de Tim Maia assinala a mudança de posicionamento da autora, dantes medrosa e agora disposta a "navegar" por "mares nunca dantes navegados", assumindo os riscos e desafios impostos pelo Programa. Dessa forma, o relato gera um efeito de concordância com a proposta da Olimpíada, o que é favorável à sua análise pela equipe de avaliação do concurso.

LUNA, T. S.; CUNHA, D. A. C. 0 discurso outro em narrativas ficcionais e não ficcionais Todo conteúdo da Linha D'Água está sob Licença Creative Commons Attribution-NonCommercial 4.0 International License 
Linha D'Água (Online), São Paulo, v. 31, n. 3, p. 167-190, set.-dez. 2018

\section{Considerações finais}

Há certa similaridade entre os relatos e as crônicas quanto às marcas ou traços de RDO mobilizados, pois ambos recorrem com frequência à citação indireta, principalmente na sua modificação analítico-objetual, e às alusões. Ou seja, oscilam entre o estilo linear e o pictórico para representar a interação entre o enunciado autoral e os alheios (VOLOCHÍNOV, [1929] 2017). Nos dois gêneros, a MAE por meio das alusões assinalam a criatividade autoral, exigida pelos critérios de avaliação da OLPEF, promovendo a imagem de um sujeito-autor com amplo repertório cultural, assim como a de um sujeito-avaliador que possui conhecimento suficiente para reconhecê-las e interpretá-las.

Vale ressaltar, entretanto, que há peculiaridades típicas das condições de produção e circulação de cada gênero. A crônica enquanto ficção prescinde da veracidade exigida em um relato de prática. A menor incidência da citação direta nos relatos pode ser atribuída à dificuldade de a memória discursiva resgatar os dizeres outros em suas próprias palavras, destacando-se, assim, a citação indireta. O DI permite aos docentes recuperarem seus atos de falas e a organização dos encaminhamentos didáticos dados ao longo das oficinas.

Nas crônicas, contudo, o DI apresenta o conteúdo semântico do enunciado alheio e funciona como discurso introdutor do DD - discurso direto preparado -, caracterizando o modo de dizer da personagem ou a avaliação apreciativa que $o$ narrador faz de seu discurso. A recorrência da MAE nesse gênero decorre possivelmente da apropriação pelos alunos de uma estratégia mobilizada nas crônicas que compõem a antologia da OLPEF. Embora nem as alusões nem as aspas sejam tematizadas no material didático, um dos textos explorados pelo Caderno do Professor (LAGINESTRA, PEREIRA, 2014) é "A última crônica" de Fernando Sabino, que alude aos versos de "O último poema" de Manuel Bandeira, ao longo de sua construção.

Tanto as crônicas como os relatos apresentam uso esparso do DIL. As razões, no entanto, diferem. As crônicas são escritas por autores iniciantes que apresentam dificuldade em mobilizar certas formas de RDO, tanto que exploram, em média, apenas um ou dois tipos de heterogeneidade mostrada. Sobressaem-se, pelo teor

LUNA, T. S.; CUNHA, D. A. C. 0 discurso outro em narrativas ficcionais e não ficcionais Todo conteúdo da Linha D'Água está sob Licença Creative Commons Attribution-NonCommercial 4.0 International License 
Linha D'Água (Online), São Paulo, v. 31, n. 3, p. 167-190, set.-dez. 2018

narrativo elaborado, aquelas que fizeram uso da estrutura dialogal tradicionalmente estabelecida, com recurso às aspas ou aos travessões, para materializar o fluxo discursivo das personagens, provavelmente inspiradas nas estratégias mobilizadas por uma das crônicas estudadas no Caderno do Professor (LAGINESTRA, PEREIRA, 2014), “Cobrança”, de Moacyr Scliar, composta quase que exclusivamente por diálogos.

Além da incipiente competência narrativa da maioria dos estudantes, o uso pouco diversificado dos esquemas de transmissão do discurso outro e das formas de RDO pode ser atribuído ao tratamento inadequado dado a esse assunto pelo Caderno do Professor (LAGINESTRA, PEREIRA, 2014). A exposição tradicional dos conceitos e da classificação dos tipos de discurso - direto, indireto e indireto livre - em um boxe informativo pouco favorece a compreensão dos efeitos expressivos e estilísticos que a presença do discurso outro provoca e o seu uso pelos alunos na produção cronística.

Enquanto as crônicas estudantis refletem uma competência narrativa em formação e dialogando com as orientações dadas no Caderno do Professor, os relatos de prática docentes atendem aos critérios de seleção expostos no regulamento do concurso (OLIMPÍADA, 2016). Assim, seguem as configurações próprias desse gênero, como a credibilidade no narrar a experiência, o que destoa de enunciados ambíguos e bivocais e explica a pequena presença do DIL. $\mathrm{E}$, devido à maior autonomia discursiva de seus autores, os relatos costuram variadas formas de RDO em sua construção, atendendo de modo mais efetivo que as crônicas ao critério da originalidade.

\section{Referências}

ALVES, Sirlei de S. R. Professor: artista de muitos palcos. 2015. Disponível em: <https://www. escrevendoofuturo.org.br/conteudo/formacao/na-pratica/relatos-de-pratica/artigo/1777/relatos-de-pratica-vencedor-2014-prof-sirlei-de-souza-ribeiro-alves>. Acesso em: 05 fev. 2018.

LUNA, T. S.; CUNHA, D. A. C. 0 discurso outro em narrativas ficcionais e não ficcionais Todo conteúdo da Linha D'Água está sob Licença Creative Commons Attribution-NonCommercial 4.0 International License 
Linha D'Água (Online), São Paulo, v. 31, n. 3, p. 167-190, set.-dez. 2018

AUTHIER-REVUZ, Jacqueline. [1982] Heterogeneidade mostrada e heterogeneidade constitutive: elementos para uma abordagem do outro no discurso. In: Entre a transparência e a opacidade: um estudo enunciativo do sentido. Porto Alegre: EDIPUCRS, 2004, p. 11-80.

Méta-énonciation et (dé) figement: le préfabriqué et l'imprévu du dire. Cabiers du Français Contemporain, 'La locution en discours', v. 1, n. 2, p. 17-39, 1995.

. Palavras incertas: as não-coincidências do dizer. Campinas/SP: Editora da Unicamp, 1998.

Dire à l'autre dans le déjà-dit: interférences d'altérités - interlocutive et interdiscursive au cour du dire. In: C. U. Lorda Mur. Polifonia e intertextualidad en el dialogo. Madrid : Oralia, Arco Libros, 2012. p. 19-44.

[2004] A representação do discurso outro: um campo multiplamente heterogêneo. Tradução por Heber Costa e Silva e Dóris Cunha. Revista Investigaçôes, v.28, número especial, p. $1-39,2015$.

BERTAZZO, Veralice M. Z. Navegar é preciso. 2015. Disponível em: <https://www.escrevendoofuturo.org.br/conteudo/formacao/na-pratica/relatos-de-pratica/artigo/1723/relatos-de -pratica-vencedor-2014-prof-veralice-maria-zawaski-bertazzo>. Acesso em: 05 fev. 2018.

COSTA, José E. P. Uma dose de palavras: um novo ser. 2015. Disponível em: < https://www. escrevendoofuturo.org.br/conteudo/formacao/na-pratica/relatos-de-pratica/artigo/1747/relatos-de-pratica-vencedor-2014-prof-jose-elonilson-parente-da-costa>. Acesso em: 05 fev. 2018.

CUNHA, Celso; CINTRA, Lindley. Nova gramática do português contemporâneo. 5. ed. Rio de Janeiro: Lexikon, 2008.

CUNHA, D.A.C. Discurso outro e ponto de vista na construção do gênero perfil jornalístico. Investigações (Online), v. 28, p. 1-49, 2015.

Formas de presença do outro na circulação dos discursos. Bakbtiniana, São Paulo, v.1, n.5, p. $116-132,1^{\circ}$ semestre 2011.

DOLZ, Joaquim; SCHNEUWLY, Bernard. Gêneros orais e escritos na escola. Tradução e organização: Roxane Rojo; Glaís Sales Cordeiro. Campina/ SP: Mercado de Letras, 2004.

LUNA, T. S.; CUNHA, D. A. C. 0 discurso outro em narrativas ficcionais e não ficcionais Todo conteúdo da Linha D'Água está sob Licença Creative Commons Attribution-NonCommercial 4.0 International License 
Linha D'Água (Online), São Paulo, v. 31, n. 3, p. 167-190, set.-dez. 2018

LAGINESTRA, Maria A.; PEREIRA, Maria I. A ocasião faz o escritor: caderno do professor: orientação para produção de textos. 4 ed. SP: CENPEC, 2014.

OLIMPÍADA de Língua Portuguesa Escrevendo o Futuro. Regulamento. 2016. Disponível em: $<$ https://www.escrevendoofuturo.org.br/arquivos/5626/olp216-regulamento-24fev2016-ok. pdf>. Acesso em: 16 jan. 2018.

Textos finalistas: edição 2014. 2014. Disponível em: <https://www.escrevendoofuturo. org.br/arquivos/5306/textos-finalistas2014.pdf>. Acesso em: 18 jan. 2018.

REBELO, Vanicleia de O. S. Pelos caminhos do aprendizado. 2015. Disponível em: <https:// www.escrevendoofuturo.org.br/conteudo/formacao/na-pratica/relatos-de pratica/artigo/1822/ relatos-de-pratica-vencedor-2014-prof-vanicleia-de-oliveira-sousa-rebelo>. Acesso em: 05 fev. 2018.

SÉRIOT, Patrick. Volosinov e a filosofia da linguagem. Tradução de Marcos Bagno. São Paulo: Parábola Editorial, 2015.

VOLÓCHINOV, Valentin. [1929]. Marxismo e filosofia da linguagem. Tradução por Sheila Grillo e Ekaterina Vólkova Américo. São Paulo: Editora 34, 2017.

Recebido: 27/02/2018.

Aprovado: 11/06/2018.

LUNA, T. S.; CUNHA, D. A. C. 0 discurso outro em narrativas ficcionais e ñ̃o ficcionais Todo conteúdo da Linha D'Água está sob licença Creative Commons Attribution-NonCommercial 4.0 International license 